\title{
CIRCULACIÓN INTERNACIONAL DE MODELOS POLÍTICOS EN LA ERA POSTNAPOLEÓNICA: CULTURA, DEBATE Y EMULACIÓN CONSTITUCIONALES ${ }^{1}$
}

\section{International Circulation of Political Models in the Post-Napoleonic Age: Constitutional Culture, Debate and Emulation}

\author{
JUAN LUIS SIMAL \\ Universidad Autónoma de Madrid \\ juan.simal@uam.es
}

Cómo citar/Citation

Simal, J. L. (2017).

Circulación internacional de modelos políticos en la era postnapoleónica: cultura, debate y emulación constitucionales.

Revista de Estudios Políticos, 175, 269-298. doi: http://dx.doi.org/10.18042/cepc/rep.175.09

\section{Resumen}

En los años inmediatamente posteriores al fin del Imperio napoleónico (18141823), el constitucionalismo, una de las principales herencias de la Era de la Revolución, no solo no desapareció como muchos de los reaccionarios al frente del proyecto de la Restauración pretendían, sino que se convirtió para un gran número de europeos de diversas tendencias políticas — que incluían a liberales de diferentes persuasiones, pero también a realistas y conservadores - en el instrumento necesario para la organización de los nuevos Estados. Este artículo analiza la evolución del gobierno constitucional en la Europa de la Restauración, enfatizando el marco internacional en el que se desarrolló el debate acerca de sus diversas variantes, y empleando como herramientas de análisis los conceptos de cultura y emulación constitucional.

Este artículo ha sido realizado en el marco del proyecto HAR2012-32713 del Plan Nacional de $\mathrm{I}+\mathrm{D}+\mathrm{i}$. 


\title{
Palabras clave
}

Constitución; liberalismo; Restauración; historia transnacional.

\begin{abstract}
In the years immediately following the end of the Napoleonic Empire (18141823), constitutionalism, one of the main legacies of the Age of Revolution, did not disappear as many of the reactionaries of the Restoration wanted. Rather, it became for many Europeans of diverse political tendencies - including liberals of various persuasions, but also royalists and conservatives - the necessary instrument for the organization of new states. This article analyzes the evolution of constitutional government in Restoration Europe, emphasizing the international context in which the debate about its various forms developed, using as analytic tools the concepts of constitutional culture and emulation.
\end{abstract}

\section{Keywords}

Constitution; liberalism; Restoration; transnational history. 


\section{SUMARIO}

I. INTRODUCCIÓN. II. ¿̇UNA NUEVA CULTURA CONSTITUCIONAL? III. EL DEBATE CONSTITUCIONAL EUROPEO, 1812-1820. IV. LA EMULACIÓN CONSTITUCIONAL, 1820-1825. V. CONCLUSIÓN. BibLIOGRAFía.

\section{INTRODUCCIÓN}

Una de las cuestiones clave del periodo de la Restauración iniciado en 1814-1815, y que se extendió hasta la década de 1830, giró alrededor de la organización de los nuevos Estados surgidos tras la caída de los regímenes revolucionarios y napoleónicos, que habían transformado las estructuras institucionales, jurídicas y legislativas de la mayor parte de Europa. A pesar de la reacción contrarrevolucionaria llevada a cabo en el continente desde la caída de Napoleón, el concepto clave que aparecía en todas las conversaciones seguía siendo «constitución». En 1814, empleando un lenguaje común entre los pensadores reaccionarios, el publicista realista francés $\mathrm{M}$. Ducancel aseguraba que una «fiebre de constituciones moldea Francia desde 1789, y parece ser, en este momento, de alguna forma epidémica en Europa" (citado por Rausch, 2013: 226). ¿Cabe encuadrar a los enfermos de este mal en un cuadro médico afín? Escritores favorables al constitucionalismo advertían un fenómeno similar, aunque naturalmente su diagnóstico era diferente. Dominique de Pradt asociaba en 1816 el avance del «orden constitucional» con la evolución de la "civilización», y añadía: «Hace veinticinco años, el nombre de constitucional era una injuria. Hoy en día es el nombre del propio mundo. Pues no solo Francia, no solo Europa son constitucionales, también lo es la América entera, lo es toda sociedad que se congrega». De Pradt consideraba que el "movimiento» constitucional era imparable, una ley incontestable: "Nuestro siglo ha adoptado el orden constitucional como su regulador, de la misma forma que el penúltimo siglo se ciñó a las leyes de la gravitación» (De Pradt, 1816: 258-261). En 1830, el pensador y activista alemán Karl von Rotteck afirmaba que «esta es claramente la era de la Constitución» (citado por Prutsch, 2013: 69). Para muchos europeos y americanos de diversas tendencias políticas, el constitucionalismo era al mismo tiempo una de las principales herencias de la Revolución, y la única herramienta capaz de organizar unos 
Estados y sociedades que se encontraban en un momento de extrema agitación tras décadas de continuas convulsiones revolucionarias.

Este artículo analiza la evolución del gobierno constitucional en la Europa de la Restauración, enfatizando el marco internacional en el que se desarrolló el debate acerca de sus diversas variantes, y empleando como herramientas de análisis los conceptos de cultura y emulación constitucional. En primer lugar, se plantea si es apropiado hablar de la existencia en Europa de una cultura constitucional transnacional con rasgos compartidos, entendiendo cultura constitucional como el contexto cultural que afecta a la formulación, interpretación y desarrollo de un texto constitucional. ¿ Se desarrolló en este periodo una cultura constitucional europea coherente, de características similares? ¿Es más apropiado hablar de varias culturas constitucionales que interactuaron entre sí? Ciertamente, el marco político de la Restauración ofrecía una variedad de alternativas, proyectos e ideales constitucionales, y en este contexto el periodo se caracterizó por la inmersión de los constitucionalismos locales en una discusión global, en un debate constitucional internacional erigido sobre precedentes ilustrados. En el seno de este constitucionalismo internacional se confrontaron modelos y se pusieron en práctica diversos ensayos constitucionales que eran conscientes de su posición en un contexto euroamericano que servía de marco de referencia, confrontación y apelación, y en el que la emulación de modelos constitucionales se convirtió en un mecanismo de cambio político.

\section{II. ¿UNA NUEVA CULTURA CONSTITUCIONAL?}

La primera cuestión a la que estas herramientas de análisis nos enfrentan es dilucidar si de la Era de las Revoluciones surgió una cultura constitucional nueva, esencialmente diferente de la cultura constitucional del Antiguo Régimen, que había estado basada en una interpretación de la constitución como ley fundamental, pero no como código surgido de una asamblea constituyente basada en la soberanía nacional y/o popular. Para ello, además de considerar las fuentes doctrinales de los diversos modelos constitucionales, es provechoso poner en relación sus ámbitos de sociabilidad, aculturación y transmisión, sus simbolismos e imaginarios, sus posicionamientos históricos y geográficos y, en fin, sus horizontes de expectativas. Todo ello con el propósito de plantear la cuestión de si es conveniente ubicar estos rasgos en el ámbito de la existencia de una o varias culturas constitucionales. Entiendo cultura constitucional —un concepto confuso y un tanto vago- como el «basamento cultural» de un texto constitucional, el «contexto cultural que es relevante para el texto constitucional, su formulación, su interpretación y su desarrollo» (Vorländer, 2012: 21). Al hacer énfasis en los plurales discursos y prácticas asociados 
a una constitución — que no solo reflejan un texto particular, sino que participan performativamente en la elaboración de una realidad constitucional-, esta es una herramienta de análisis que bebe del concepto de cultura política (Pérez Ledesma y Sierra, 2010; Cabrera y Pro, 2014) y que se enriquece notablemente al complementarlo con un análisis de la cultura visual del constitucionalismo (Reyero, 2010). Cultura constitucional quiere hacer referencia, en definitiva, a las múltiples dimensiones que una constitución puede adoptar, entre ellas sus tecnicismos jurídicos, sus expresiones simbólicas, su capacidad para convertirse en un punto de referencia capaz de delimitar opciones ideológicas y generar identidades políticas, sin olvidar su potencial como fuente de integración, polarización o división de una sociedad.

El significado de "constitución", en su acepción de constitución política, fue fuertemente disputado en el periodo revolucionario y posrevolucionario, enmarcado en un debate que se retrotraía siglos atrás, pero que se había explicitado en torno a un constitucionalismo de carácter moderno desde mediados del siglo XviII. Las múltiples constituciones surgidas de las revoluciones norteamericana y francesa produjeron una riquísima discusión teórica y trajeron consigo una transformación de las fuentes del poder político a través de la introducción de novedades como el principio de soberanía nacional, la protección de los derechos del hombre o la legitimidad del poder constituyente. El problema de su plasmación práctica fue solucionado a través de la elaboración del concepto de gobierno representativo y de la autolimitación del poder a través de la ingeniería constitucional. Todo ello fundado sobre el principio de la constitución como norma suprema (Wood, 1969; Dippel, 2009).

Pero no solo en aquellos países donde se dió un debate intenso propiciado por una Ilustración de fuerte carácter político, como Francia o el mundo anglosajón, surgió un constitucionalismo potente. También en otras geografías existió una "manía» constitucional, aunque en su extensión fue clave el impulso proveniente de Francia. Las constituciones francesas fueron exportadas a toda Europa, adoptando una amplia gama de formas. Las establecidas por Napoleón en diversas zonas de Europa (Reinos de Holanda, Nápoles, Westfalia y España, y el Ducado de Varsovia) contaron con un significativo apoyo local, mayor o menor dependiendo del contexto, y fueron un paso clave en el proceso general de constitucionalización de las monarquías europeas que tuvo lugar en el primer tercio del siglo xix (Hill, 1936). Pero las constituciones surgidas en Europa en el contexto de las guerras napoleónicas no solo tuvieron raíces francesas. También aparecieron influyentes textos constitucionales promovidos por los enemigos de Napoleón. Así, los británicos implantaron en 1812 en la Sicilia ocupada una constitución moldeada según el modelo inglés, y los patriotas españoles redactaron la Constitución de Cádiz en paralelo al desarrollo de la guerra contra el invasor francés. 
En el caso de la monarquía hispana, el proceso trajo consigo una transformación de la cultura constitucional monárquica propiciada por la confluencia del pensamiento ilustrado con tradiciones de gobierno locales, que desembocaría en Cádiz en 1812. En este debate preconstitucional se pueden trazar los orígenes de la cultura constitucional liberal hispana que daría lugar a la primera Constitución española. Plasmado en algunos proyectos constitucionales planteados en el contexto del absolutismo ilustrado, este debate se alimentó de lo que se podría calificar como constitucionalismo ilustrado. De cuestiones relacionadas con el estudio de la ciencia del gobierno y de la nueva disciplina de la economía política, pensadores como Valentín de Foronda, el conde de Cabarrús, León de Arroyal, Manuel de Aguirre o Victorián de Villava pasaron a discutir acerca de la necesidad de articular una constitución política que enunciara nuevas formas de representación en el seno de la monarquía (Portillo Valdés, 2000 y 2007; García Monerris, 2011; Fernández Sarasola, 2004 y 2015; Morelli, 2006). Estas reflexiones teóricas fueron transformadas en proyectos reales una vez iniciada la crisis de 1808, por la que España entraba plenamente en la Era de la Revolución. Tras la formación de unas Cortes constituyentes depositarias de la soberanía nacional, el resultado fue la Constitución de 1812, que trasmutó el carácter constitucional de la monarquía y las relaciones entre la nación y su gobierno, poniendo en pie una profunda reforma a través de la transformación de la crisis de la monarquía en crisis constitucional (Portillo Valdés, 2000 y 2006; García Monerris, 2003). Este cambio en las fuentes de la soberanía y en las instituciones que la representaban vino acompañado de una amplia transformación en la esfera pública, que en un ambiente de libertad de expresión desconocido hasta entonces permitió el desarrollo de debates constitucionales que superaron los entornos y registros elitistas que habían delimitado el constitucionalismo ilustrado. Una cultura constitucional con rasgos diferenciados, basada en el racionalismo ilustrado, la discusión pública y la doctrina revolucionaria del poder constituyente se instaló en España, insertada en un contexto internacional en el que las transformaciones constitucionales reflejaban cambios en todas las esferas de la vida pública. De las raíces en transformación de este modelo germinó a finales del siglo XVIII y principios del xIX en el mundo euroamericano un constitucionalismo moderno, surgido de fuentes ilustradas y de los efectos del proceso revolucionario francés y estadounidense, un constitucionalismo racional-normativo anclado en la pretensión de transformar el presente (Dippel, 2009; Fernández Sarasola, 2015).

Este primer espacio constitucional euroamericano se intentó reconstruir con mimbres similares pero objetivos diferentes durante la Restauración. La necesidad de dotar a los Estados restaurados de una constitución no era una reclamación que viniera únicamente de las filas de la oposición (revolucionaria 
o no) al orden instalado en el Congreso de Viena (1814-1815), sino que era una alternativa contemplada por pensadores y, sobre todo, políticos en activo que se enfrentaban al desafío de establecer regímenes duraderos en una Europa que no podía volver a someterse a las mismas fuentes de legitimidad tras la experiencia revolucionaria.

En este sentido, en las filas restauradoras no existió unanimidad acerca de los métodos que debían emplearse para asegurar la paz y el orden, y no solo los liberales acudieron al lenguaje constitucional. Mientras que en la cuna de la revolución, Francia, se instalaba en 1814 un régimen de carta otorgada que reconocía un mínimo de libertades y de representación política, en la mayor parte de Europa se abandonaron los sistemas constitucionales, equiparados por los pensadores y políticos reaccionarios con la revolución. Así, en España y en Piamonte Fernando VII y Víctor Manuel I adoptaron posiciones plenamente reaccionarias instalando sendas monarquías neoabsolutistas. La posición del canciller austriaco Metternich, considerado el principal arquitecto del orden diseñado en Viena, pasaba por una oposición total a la instalación de regímenes que reflejaran en el más mínimo aspecto la pervivencia de la herencia revolucionaria. La posición de Rusia — que durante las guerras napoleónicas había afianzado su condición de gran potencia europea- era variable, dependiente de la voluntad del zar Alejandro, preocupado por asegurar el orden pero capaz de ofrecer gestos que parecían reflejar la continuación de su moderada aproximación a la reorganización política de Europa, como la concesión a la Polonia integrada en su imperio de un código aperturista que daba continuidad a una tradición constitucional local que ya en 1791 había instaurado una monarquía constitucional (Ghervas, 2008; Jarrett, 2013; Vick, 2014).

Sin embargo, a ojos de algunas élites, la Restauración necesitaba además construir una nueva legitimidad, o al menos renovar la legitimidad monárquica tradicional, al tiempo que debía enfrentarse a las corrientes políticas que mantenían que esa legitimidad debía construirse a través del establecimiento de regímenes constitucionales. Para ello, algunos sectores de los poderes restaurados recurrieron al constitucionalismo, aunque fuera de manera selectiva, y al hacerlo se enfrentaron a aquellos que se oponían por completo a la adopción selectiva del legado revolucionario. En la Restauración hubo proyectos políticos que fueron más allá de la pura reacción, conformando un conservadurismo constitucionalista posibilista, enfrentado en el seno de los intereses de orden a ciertos sectores plenamente contrarrevolucionarios que se irían agrupando en torno al ultrarrealismo. La propuesta de esta familia conservadora europea pasaba por ofrecer un constitucionalismo monárquico en el que el rey retuviera la supremacía política, pero en el que los límites a su actuación estuvieran recogidos en una constitución escrita "otorgada» por él mismo (Prutsch, 2014). Este era el modelo de la Carta otorgada francesa de 1814, al 
que se comprometieron los Estados alemanes en el Acta Federal de junio de 1815, y que se mantendría como uno de los modelos fundamentales en los recurrentes debates de la década siguiente. A la tarea de llevar a cabo reformas políticas dedicaron sus esfuerzos personalidades de la Restauración como Luis XVIII, el canciller prusiano Hardenberg, o muchos de los dirigentes de los Estados alemanes sudoccidentales. Esta postura tuvo también notables defensores en los diversos Estados italianos, en España y en Portugal. Desde este punto de vista, el equilibrio geoestratégico establecido en Viena debía complementarse no solo con represión y vigilancia de la oposición liberal, sino que debía incluir también un equilibrio de poder entre la corona y unas instituciones representativas que había que conservar o constituir, según los casos. Este equilibrio interno político sería asegurado a través de textos constitucionales de diferente alcance, que de todas formas encontraron dificultades para su consolidación al despertar animadversión a izquierda y derecha.

En cualquier caso, la situación seguía siendo percibida como esencialmente retrógrada por amplios sectores de lo que empezaba a conocerse como liberalismo, y fue pronto impugnada a lo largo de todo el continente. Ante el retroceso de libertades y derechos reconocidos, y frente a la respuesta represiva de los Estados de la Restauración, cada vez más miembros de la oposición liberal recurrieron a métodos conspirativos y revolucionarios. A partir de 1814 los sectores descontentos de numerosas sociedades europeas exigieron la (re) adopción de sistemas constitucionales, pero hasta 1820 no se produjo una alteración significativa del orden establecido en Viena. El movimiento revolucionario iniciado en enero de ese año en España, y pronto extendido a Nápoles, Portugal y Piamonte, tenía en el establecimiento de una constitución su elemento central. La Constitución de Cádiz se convirtió en el texto de referencia de estos movimientos, y fue adaptada a diferentes contextos. La adopción del modelo constitucional español fue el resultado de intensos debates desarrollados a nivel nacional e internacional acerca de las ventajas e inconvenientes que ofrecían los diferentes modelos constitucionales disponibles en la Europa del momento, que solían incluir menciones a ideas preconcebidas y a prejuicios sobre el carácter nacional de los pueblos. Estas discusiones giraron, principalmente, en torno a dos opciones: la ofrecida por la Carta otorgada francesa de 1814, y la brindada por la Constitución española de 1812, siempre con la presencia de la constitución británica (no escrita) al fondo.

\section{EL DEBATE CONSTITUCIONAL EUROPEO, 1812-1820}

Dominique de Pradt afirmó en 1816 que el constitucionalismo sería perfeccionado a través de un debate internacional: «las comunicaciones 
establecidas entre todos los pueblos, las comparaciones, las discusiones le servirán de vehículo» (De Pradt, 1816: 260). Ciertamente, la intensidad de los debates vividos en Europa en esos años, con continuas referencias en todos los países a modelos y experiencias foráneas, apunta hacia la importancia que tuvieron para el desarrollo constitucional las transferencias políticas y culturales en diversas dimensiones transnacionales.

En Europa, las reflexiones sobre el constitucionalismo solían comenzar con consideraciones sobre la constitución de Gran Bretaña. La constitución inglesa, aunque imposible de adoptar fielmente por carecer de un texto escrito, rondó todos los debates constitucionales del periodo. Sirvió como inspiración o modelo para muchos europeos que generalmente habían accedido a ella, idealizándola, a través de las interpretaciones de populares autores como el francés Montesquieu, el suizo J. L. De Lolme o el británico William Blackstone, que en gran parte no recogían sus implicaciones parlamentarias surgidas de la práctica de gobierno en el siglo anterior, y la entendían como prototipo de constitución mixta (Varela Suanzes-Carpegna, 2013 y 2015). La influencia del modelo inglés en figuras del nuevo constitucionalismo, como Benjamin Constant o los prestigiosos doctrinarios franceses François Guizot y Pierre-Paul Royer-Collard, contribuyó a la expansión de la anglofilia constitucional inglesa por el continente (Rosanvallon, 1985; Varela Suanzes-Carpegna, 1992; Jaume, 2003). En cualquier caso, el modelo inglés no solo se transmitió a través de influencias doctrinales, sino que también lo hizo a través de iniciativas efectivas de las autoridades británicas. Así, la constitución inglesa fue el modelo impuesto en la redacción de la Constitución siciliana de 1812, que tendría cierto recorrido en la Península italiana en los años siguientes.

En cambio, para un sector del liberalismo europeo crítico con el conservadurismo posrevolucionario, la Constitución española de 1812 llegó a convertirse en contramodelo de la británica. Además de sus aspectos doctrinarios, jurídicos y de organización política, es esencial tener en cuenta la cultura constitucional a ella asociada y su circulación internacional. Resulta conveniente revisar este aspecto, no solo con el propósito de reexaminar la importancia de la Constitución de 1812 para el desarrollo de las culturas constitucionales iberoamericanas y europeas — especialmente en el sur del continente-, sino también para apreciar los puntos en común que el caso español tuvo con otras culturas constitucionales, surgidos tanto por la transferencia e influencia del texto gaditano como por procesos de evolución desde culturas políticas previas con rasgos similares. Esto implica considerar las polémicas, rechazos y críticas cosechadas por la Constitución de 1812 dentro de un complejo y fluido proceso de creación de una cultura constitucional trasnacional.

El texto gaditano era relativamente bien conocido, y fue analizado, alabado o criticado por numerosos pensadores de diversas nacionalidades. 
Además de su impacto en Nápoles, Piamonte, Portugal e Iberoamérica (Schmidt-Nowara, 2012; Eastman y Sobrevilla Perea, 2015), la Constitución de 1812 fue estimada por la oposición liberal francesa, discutida en Gran Bretaña y en los Estados alemanes, mitificada por los decembristas rusos, e incluso celebrada en la India colonial. La traducción inglesa que apareció en Filadelfia en 1814 aseguraba que era la constitución «más liberal, sabia y duradera que es posible adoptar en una monarquía limitada, e incluso muy superior a las cacareadas de muchos gobiernos republicanos» ${ }^{2}$.

Pero la Constitución española no significaba lo mismo para todos aquellos que la avalaron o condenaron. No fue entendida de la misma manera, y tuvo diferentes significados para diferentes personas. Ya desde 1812 fue interpretada desde divergentes puntos de puntos de vista, por personas socializadas en diferentes contextos, y en ocasiones con fines completamente diferentes e incluso opuestos. Los exégetas de la Constitución de Cádiz la interpretaron en función de sus diferentes niveles de familiaridad con la historia o la lengua española — los que no leían español la conocieron a través de versiones de segunda mano o con las muchas traducciones que muy pronto aparecieron en los principales idiomas europeos- $y$, naturalmente, ofrecieron lecturas mediadas por sus expectativas, sus condiciones locales y sus proyectos particulares.

Que la Constitución española fuera un texto que combinaba aspectos plenamente revolucionarios con otros pertenecientes a la esfera católica — como la confesionalidad de la nación y el Estado - favorecía la diversidad de interpretaciones. El reaccionario Carl von Haller la calificó como una «extraña amalgama entre el Espíritu Santo y el espíritu del siglo, entre el jacobinismo y la religión católica», mientras que René de Chateaubriand se preguntaba: «¿Cómo se las arreglaron [los españoles] para incorporar tanta monarquía en la religión y tanta democracia en la política?». Este carácter «híbrido [...] transicional e impuro» —en palabras del historiador Javier Fernández Sebastián— está detrás de su gran maleabilidad, de que fuera objeto de elogio o condena por parte de revolucionarios o reaccionarios, liberales moderados o radicales, monárquicos o republicanos (citado por Fernández Sebastián, 2012: 55-56, 68).

Desde su promulgación en 1812, la Constitución española fue debatida en Gran Bretaña, donde interesaba la organización política de su aliado militar en la Guerra Peninsular (Fernández Sarasola, 2012). Traducida al inglés desde 1813, la mayoría de los comentaristas políticos y miembros del Parlamento se centraron en explicar las razones de lo que consideraban su fracaso. Tanto tories como whigs criticaron los aspectos de la Constitución española

2 Constitution of the Spanish Monarchy, Filadelfia, G. Palmer, 1814 (citado por Eastman, 2015: 2). 
que más se alejaban de los principios de la Constitución británica y la acercaban a la Revolución francesa: la ausencia de una segunda Cámara moderadora, la rígida separación de poderes y la restricción de las atribuciones reales. En los círculos políticos británicos estaba extendido el temor a su potencialidad revolucionaria, atribuida a filiaciones francesas. Simpatizantes del liberalismo español como el líder whig lord Holland también la criticaron, aunque como él muchos mantuvieron que estos errores eran de fácil solución, y culpaban de la inestabilidad del país a la actuación de Fernando VII (Moreno Alonso, 1997). En cualquier caso, el rechazo a la Constitución española era generalizado entre las principales figuras del Gobierno, siguiendo la opinión del duque de Wellington, que había convivido con las Cortes durante su estancia en la Península.

En Francia, la Constitución española tuvo una presencia en el debate acerca del nuevo orden político del país al menos comparable a la que tuvieron las propias constituciones francesas. Rápidamente traducida tras la caída de Napoleón, su ejemplo — favorecido por su pedigrí antinapoleónico- fue empleado en 1814 para proponer una constitución para Francia que combinara la soberanía nacional con el principio monárquico. Pero en el clima político mayoritariamente conservador de la Restauración francesa la Constitución española fue mayoritariamente criticada desde diversos puntos de vista. Los reaccionarios vieron en ella el último elemento remanente de la época revolucionaria. Muchos, como Chateaubriand, consideraban que era republicana en espíritu - para condenarla por su radicalidad - mientras que otros conservadores la consideraban inadecuada para España por ser demasiado avanzada para el carácter, la ilustración y la virtud del pueblo español, y por lo tanto destinada al fracaso. Esta era también la opinión de gran parte del liberalismo posrevolucionario francés. Los principales teóricos franceses (como Constant o Guizot) apreciaban su rol como instrumento de cambio político pero consideraban que la monarquía que diseñaba era impracticable. Argumentaban que un texto como el español, tan parecido a la Constitución de 1791, llevaría irremediablemente al país a un caos similar al que había sido conducida la monarquía constitucional francesa. Como sucedía con muchos británicos, sus críticas se centraban en el monocameralismo, y recomendaban la instalación de un senado, así como la introducción de la principal innovación institucional surgida de su pensamiento: un poder neutro moderador. En cualquier caso, fue el modelo británico el que más apoyos recabó en la Francia de la Restauración borbónica, como quedó finalmente reflejado en la Charte otorgada por Luis XVIII el 4 de junio de 1814 (Crăiuçu, 2003; Alexander, 2003; Aguilera, 2011; Basabe, 2012; Demier, 2012).

En Italia, la Constitución española era conocida, había sido traducida y circulaba entre los círculos ilustrados. La recepción de la Guerra de la 
Independencia española contribuyó a introducir en el pensamiento político italiano el mito del modelo revolucionario español. Muchos italianos veían en el ejemplo que había dado el pueblo español en la lucha contra el invasor extranjero una manera de fortalecer el sentimiento nacional. También apreciaban la paralela revolución popular regeneradora que terminó por producir la Constitución de Cádiz. El caso español reforzaba la interpretación, que empezaba a extenderse por Italia, de que las luchas de liberación nacional y política iban de la mano.

En Portugal no había surgido durante la guerra un movimiento constitucional similar al español —en buena parte porque la familia real había conseguido escapar de Napoleón y seguía gobernando desde Brasil—, pero a partir de entonces, y con el ejemplo español muy cerca, invocar el constitucionalismo implicaba nítidamente mantener una postura antiabsolutista. En el contexto de una monarquía dividida desde la instalación de la corte en Río de Janeiro, los partidarios de una reforma de la monarquía que sirviera no solo para mantenerla unida sino también para transformarla en pos de su regeneración, acudían a la necesidad de proclamar una constitución. Esta no tenía por qué estar necesariamente asociada a la revolución, argumentaban sus partidarios. La prensa forzada a expresarse desde el exilio reclamaba una constitución advirtiendo que no se le debía temer, pues en realidad «aumenta el poder y dignidad del trono» ${ }^{3}$. Lejos de aspiraciones republicanas, que sí se dieron en Brasil, los conspiradores portugueses encarcelados en 1817 reclamaban una regeneración de la monarquía a través de una constitución escrita, con el modelo español como referencia fundamental.

Las noticias de la revolución constitucional española habían llegado hasta Rusia. No faltaban aquellos que veían en España un ejemplo aplicable al imperio de los zares. Alejandro I promovía en esos años una política reformista que incluyó en julio de 1812 el reconocimiento de las Cortes españolas y de su constitución en el Tratado de Velikiye Luki. Alejandro hizo además numerosas declaraciones y acciones que hacían posible ver en él un monarca ilustrado e incluso liberal. No solo apoyó la instalación del régimen de carta otorgada en la Francia de la Restauración, sino que su política hacia Polonia permitía a algunos esperar la toma de medidas similares en Rusia. En la inauguración del Parlamento polaco (Sejm) en marzo de 1818, el zar pronunció un discurso en el que abría la puerta a aplicar al resto del imperio un gobierno constitucional similar al que había sido otorgado a Polonia en noviembre de 1815. Pero su progresivo viraje hacia la reacción, poniéndose al frente de la contrarrevolución europea, impulsando la Santa Alianza, y confiando su

3 O Portuguez (citado por Paquette, 2013: 127). 
política interior al ultraconservador conde Aleksei Arakcheev, frustró profundamente las esperanzas de muchos de los miembros más destacados de una generación formada en los valores patrióticos y de libertad que habían figurado en el debate intelectual ruso desde principios de siglo. En el seno de este patriotismo moderno tal y como era interpretado por ciertos sectores de la sociedad rusa - especialmente entre aquellos que vinculaban el patriotismo con la lucha por la libertad, en un proceso similar al sucedido en muchos otros lugares de Europa - destacaba la aspiración de que el monarca otorgara una constitución. Los futuros decembristas Nikita Muraviev y Pavel Pestel redactaron en estos años sendos proyectos de constitución en los que se aprecian influencias del texto español (Alexeeva, 2011; Rabow-Edling, 2012; Offord, 2012).

El recorrido internacional de la Constitución de Cádiz afectó a los propios liberales españoles. Entre 1814 y 1820 tuvieron lugar en España una sucesión de pronunciamientos, organizados a través de plataformas clandestinas y redes masónicas, y protagonizados por una coalición de civiles y militares. Su objetivo era reinstalar en España una monarquía constitucional, aunque que esta fuera la diseñada en Cádiz no era indispensable. Durante estos años la Constitución de 1812 fue sometida a crítica por parte de algunos liberales, algunos de ellos exiliados en Francia e Inglaterra, y su modificación entraba dentro de los planes de muchos de los que con más energía se dedicaron a planear el fin del gobierno absoluto de Fernando VII. Así, los conspiradores del llamado Plan Beitia incluían una modificación en línea moderada de la Constitución de 1812 (Morange, 2006). Todas las tentativas conspirativas fracasaron hasta que la liderada por Quiroga y Riego en los alrededores de Cádiz en enero de 1820 consiguió forzar a Fernando VII a jurar la Constitución de 1812. Sin embargo, en los primeros momentos de la revolución, las referencias al modelo de cambio político propuesto no se centraban necesariamente en el ejemplo gaditano, sino que este se dejó estratégicamente abierto a otras posibilidades.

Entre algunos liberales españoles crecía la influencia de la práctica y la teoría constitucional puesta en marcha en Francia, inspirada en el modelo británico. La Carta otorgada francesa de 1814 era fruto de un compromiso entre un rey capaz de percibir su precaria situación en el país, y los intereses sociales herederos de la transformación revolucionaria y napoleónica. Los límites a la autoridad real establecidos en la Carta dejaron un gran descontento entre los sectores más reaccionarios de la sociedad francesa. Para los más retrógrados, suponía toda una claudicación. Luis XVIII se enfrentó a una dura oposición ultra, que paradójicamente no renunció a emplear la parlamentarización de la monarquía francesa para bloquear el desarrollo constitucional (Alexander, 2003; Demier, 2012). La Carta se convirtió en 
uno de los principales modelos de Estado posrevolucionario en Europa y vertebró - junto con la Constitución española - el debate constitucional durante la Restauración. La capacidad percibida del modelo de carta otorgada como elemento de transición desde la revolución hacia una monarquía moderadamente liberal lo hizo popular para numerosos europeos, que creían que sus principios e instrumentos (robusto poder real, bicameralismo, reconocimiento de algunas libertades) debían ser incorporados a los códigos que proyectaban para sus países. El modelo francés fue rápidamente aplicado en varios Estados alemanes con el apoyo de sectores locales que habían sido testigos del constitucionalismo bonapartista y que la consideraban un ejemplo de monarquía moderada. Estados alemanes del suroeste como Baviera o Baden llevaron a cabo reformas constitucionales que tomaron la Carta francesa como modelo. Cumplían así el requisito de la Confederación alemana de dotar a sus miembros de constituciones. Sin embargo, estas iniciativas no libraron a estos países de tensiones políticas surgidas alrededor del modelo constitucional. Realistas y liberales de diferentes tendencias se enfrentaron en torno a cuestiones como la relación entre el monarca y el Parlamento, la libertad de prensa o el sufragio. La dimensión de la protesta y agitación de la oposición liberal llevó a que la Confederación aprobara en 1819 los decretos de Carlsbad, que al restringir el debate público pretendían limitar la capacidad de los sectores sociales descontentos de reclamar una profundización en la constitucionalización de sus respectivos Estados (Prutsch, 2013; Jarrett, 2013).

La resistencia de muchos monarcas a tomar esta dirección, especialmente en el sur del continente europeo, llevó a los partidarios de la vía reformista a aceptar la necesidad de acudir a prácticas revolucionarias si se quería efectuar el cambio político. En este contexto, fue la Constitución española la que no solo fue discutida, sino también adoptada o adaptada por los movimientos revolucionarios que en 1820-1821 comenzaron en España, Nápoles-Sicilia, Piamonte y Portugal. Todos ellos tenían en el núcleo de sus objetivos políticos el principio de soberanía nacional y la formación de sistemas representativos con una mayor participación de los ciudadanos en los asuntos públicos, aspectos que debían ser garantizados por una constitución escrita. Tras un debate en el que los dos principales modelos constitucionales disponibles - el español y el francés- se confrontaron, fue la Constitución española la que finalmente sirvió de paradigma en el sur de Europa, dejando paso a la emulación política. Sin embargo, una vez asegurado el cambio constitucional, en todos estos países continuó una intensa discusión - con ramificaciones internacionales- acerca de la conveniencia de modificar el texto gaditano en sentido moderado, acercándolo a la Carta francesa. 


\section{LA EMULACIÓN CONSTITUCIONAL, 1820-1825}

El interés por la Constitución española aumentó desde su restauración en España en marzo de 1820. El canciller austriaco Metternich, adalid de la respuesta a la ola revolucionaria de 1820 , la consideraba un peligro para la estabilidad del continente. Sin embargo, en febrero de 1821 mostró su alivio porque hubiera sido adoptada como modelo por los revolucionarios del sur de Europa, ya que si estos hubieran elegido la Carta francesa - tal y como algunos de ellos habían propuesto- la intervención de los poderes de la Restauración hubiera sido más complicada al caer en una flagrante contradicción ${ }^{4}$.

Desde luego, las revoluciones constitucionales de 1820-1821 en el sur de Europa no tuvieron en la Constitución de Cádiz o en la Carta francesa sus únicos precedentes o modelos. Fueron también construidas sobre otros proyectos constitucionalistas diseñados en Italia y la península ibérica durante los años de conquista y guerra internacional previos a 1814. A las tradiciones jurídicas y de pensamiento locales se añadieron influencias extranjeras, especialmente provenientes de Francia y Gran Bretaña. Ambas potencias habían encontrado en el suelo de las penínsulas meridionales no solo un escenario bélico en el que dirimir sus conflictos, sino también un laboratorio de innovación constitucional alimentado por la politización y la vitalidad ideológica desencadenada por la expansión revolucionaria y napoleónica. Por una parte, intervinieron directamente imponiendo constituciones en los territorios que controlaban y, por otra, llevaron a cabo una labor de cooptación y divulgación de sus tradiciones constitucionales. De esta manera, varias constituciones que seguían modelos franceses fueron instaladas en Italia durante el periodo revolucionario y napoleónico. En 1808 el Estatuto de Bayona, basado en el modelo napoleónico, se convirtió en la primera norma jurídica de la monarquía española. Por su parte, los ocupantes británicos favorecieron la instalación en Sicilia de una constitución moldeada en la tradición inglesa. En la península ibérica los británicos también se inmiscuyeron en los desarrollos políticos de España y Portugal, y el análisis del contexto gaditano de 1810-1814 no puede desatender la presencia, como modelo o como amenaza, de las fuerzas británicas. Pero sin duda, fue el bonapartista Acte Constitutionnel de l'Espagne el documento que más relevancia tuvo en la península al provocar, aunque solo fuera indirectamente, la respuesta de los patriotas que luchaban contra las

4 En concreto, afirmaba que había sido afortunado que los napolitanos hubieran adoptado la "constitución de las Cortes» y no la Carta francesa, pues de otra manera hubieran puesto a la coalición interventora, de la que Francia formaba parte, en una situación embarazosa (Butrón Prida, 2006: 40). 
tropas imperiales. Precisamente por ser un texto de resistencia al «tirano», la Constitución gaditana pudo ser evocada por los constitucionalistas europeos que querían continuar la erosión del Antiguo Régimen situándose al margen de sospechosos paradigmas franceses (Busaal, 2012; Cruz Villalón, 2007; Fernández Sarasola, 2007) 5 .

Así, el sur de Europa — que contaba con lazos dinásticos y puntos de partida institucionales y culturales similares, fruto de una historia común- atravesó un proceso que contribuyó a formar un constitucionalismo mediterráneo que bebía de numerosas fuentes doctrinales, institucionales e ideológicas, originarias tanto del propio país como de los desarrollos generales del mundo euroamericano en la Era de las Revoluciones (Morelli, 2006; Romano, 2011; Rodríguez López-Brea, 2013b; Mastroberti, 2014). Esta cultura constitucional común nunca fue más intensa que durante los primeros años de la década de 1820. Esto se debió, entre otros aspectos, al hecho de que las revoluciones de la década mostraron características transnacionales importantes. El pronunciamiento de Riego fue solo la última de las varias tentativas proconstitucionales que se habían dado en España desde 1814. Nápoles y Sicilia siguieron los pasos españoles en julio de 1820, en agosto lo hizo Portugal, y en marzo del año siguiente Piamonte. Estos espacios geográficamente próximos aparecieron conectados por numerosas referencias cruzadas y préstamos teóricos y prácticos en el ámbito constitucional, aunque también por recelos y desconfianzas. El desarrollo de una cultura constitucional compartida a pesar de las diferencias locales aparece como uno de los aspectos más destacados de este proceso (Späth, 2012).

La revolución dio paso en España a un régimen constitucional basado en el código de 1812. Sin embargo, las discrepancias de interpretación sobre los principios en él recogidos y sobre la manera de aplicarlos a la realidad política dividieron al liberalismo español en diversas facciones, reunidas por la opinión pública en torno a las etiquetas de moderados y exaltados. El debate constitucional se convirtió en uno de los principales campos de batalla de la discusión política, y algunos liberales moderados llegaron a proponer la reforma de la Constitución siguiendo el modelo francés, propuesta que fue descalificada por la mayoría de los exaltados como contrarrevolucionaria. En el Reino de las Dos Sicilias, en Portugal y en Piamonte se vivieron discusiones semejantes. El eje común de la polémica residía en la introducción de una cámara alta que, en opinión de los moderados, pondría freno a los excesos del monocameralismo gaditano.

5 Sin embargo, el evidente parecido de la Constitución española con la francesa de 1791 fue esgrimido por sus críticos. 
Las tres revoluciones meridionales que siguieron a la española emularon en la práctica el modelo insurreccional español del pronunciamiento. Además de los preparativos conspirativos y de la participación de sectores militares en coalición con elementos civiles, un aspecto clave fue el uso de un poderoso símbolo capaz de movilizar a los potenciales seguidores. En los cuatro casos, este símbolo fue la Constitución española de 1812. Retrospectivamente, el piamontés Cesare Balbo afirmó en 1857 que la Constitución de Cádiz había sido «la palabra, el nombre, el estandarte, alrededor del cual se reunían todas las opiniones liberales, las esperanzas liberales de Italia» (citado por Romano, 2011: 461). Para ello, no había sido necesario que los detalles del texto español se conocieran en profundidad. De hecho, una cierta falta de conocimiento combinada con la ambigüedad característica del código gaditano podía traducirse en un instrumento más poderoso. El grado de conocimiento de la Constitución española en el Reino de las Dos Sicilias antes de 1820 es objeto de discusión entre los historiadores, pero lo que está fuera de duda es que fue bien recibida a partir de 1820 por su capacidad para adecuarse al contexto meridional italiano. Diversas tendencias políticas locales encontraron en ella un texto de consenso que aunaba liberalismo con los principios monárquico y católico, y que además proporcionaba instrumentos de organización territorial descentralizada (diputaciones provinciales y municipios) adecuados a las prácticas de administración y a las demandas de las oligarquías locales (De Francesco, 1998; Rodríguez López-Brea, 2013a; Stites, 2014; Delpu, 2014).

En Nápoles, Portugal y Piamonte la práctica de la revolución constitucional adquirió notables paralelismos con lo sucedido en España: preparativos clandestinos a cargo de sociedades secretas en los que colaboraron civiles y militares, aplicación del modelo de pronunciamiento, y una movilización iniciada en las provincias que trasladó la revolución de la periferia a los centros de poder. Los revolucionarios escogieron la Constitución española como un estandarte al que no se mostraron plenamente entregados, y que podía (y debía) ser modificado y adaptado a las circunstancias locales.

La extensión del movimiento revolucionario tras el pronunciamiento de Nola, planeado por sociedades carbonarias, llevó al monarca del Reino de las Dos Sicilias a aceptar el 7 de julio de 1820 la Constitución española. Esta debía ser adaptada por una próxima asamblea a las «circunstancias particulares» del país. Para ello se formó una junta provisional y una comisión que debía estudiar las enmiendas que se introducirían al texto español. La discusión no solo se desarrolló en el Parlamento sino que se extendió a la prensa y a puntos de reunión social como los cafés (Delpu, 2014). En octubre se formó el Parlamento y, en el discurso de apertura, su presidente Mateo Galdi alabó la Constitución española como «modelo», al ser la mejor elaborada por los 
«publicistas de Europa desde la mitad del siglo pasado hasta ahora». Por su parte, el monarca la aceptó como punto de partida del nuevo diseño institucional que debía hacerse «sobre las bases de nuestras antiguas instituciones y de las ideas que nos son familiares». El 9 de diciembre, tras la introducción de algunas modificaciones, el Parlamento aprobó el texto definitivo de la Constitución, y el 29 de enero de 1821 el monarca proclamó como «Constitución del Reino de las Dos Sicilias la Constitución española reformada por el Parlamento». Las modificaciones respecto del texto gaditano fueron pocas y no alteraron su esencia, pero se había dejado claro que la revolución constitucional napolitana seguiría criterios locales (Ferrando Badía, 1959: 40, 60-69, 71). Los carbonarios favorables a posturas democráticas habían logrado transformar la monarquía a través del esquema español, que interpretaban como igualitario. Sin embargo, seguía existiendo una postura más moderada que prefería la introducción de reformas al texto aprobado para acercarlo a la Carta francesa.

En Portugal el proceso fue similar. Tras un pronunciamiento militar que tuvo lugar en Oporto el 24 de agosto de 1820, un movimiento que reclamaba la adopción de una constitución pronto se extendió a la capital. Tras la formación de juntas, se encargó a una Junta Provisional Preparatoria de las Cortes la promoción del debate constitucional. Enseguida surgió la cuestión de en qué medida el texto español debía ser adoptado, con algunos sectores partidarios de su adopción inmediata. Como en Nápoles, la discusión giró alrededor de la forma y medida en que la Constitución española debía ser adaptada a las necesidades locales. Finalmente se llegó a un acuerdo para iniciar el proceso de elaboración de una nueva constitución, que se iniciaría con unas elecciones siguiendo el proceso establecido en el texto gaditano. Una vez reunidas las Cortes constituyentes a principios de 1821 , los diputados decidieron dotar a Portugal de una constitución propia, teniendo como referencia la española. El 9 de marzo de 1821 se aprobaron las conocidas como Bases de la Constitución. El rey Juan VI, aún en Brasil, se negó a reconocer las Cortes peninsulares, y rechazó también la posibilidad de conceder una carta constitucional por iniciativa propia, aunque tras las numerosas manifestaciones por la Constitución española que tuvieron lugar en diferentes partes de Brasil decidió regresar a Portugal. Una vez allí tuvo que reconocer las Cortes, que en septiembre de 1822 aprobaron una Constitución original, pero marcada por la influencia española (Berbel, 2008 y 2012; Mendonça, 2011; Paquette, 2012 y 2013).

Tras el éxito de los constitucionales en Nápoles, el movimiento se extendió a otros lugares de Italia, pero solo triunfó, fugazmente, en el reino de Piamonte-Cerdeña. A lo largo de 1820 se vivió en Turín una disputa entre los partidarios de la opción constitucional francesa y los de la española. El abandono del rey Víctor Manuel de los tímidos ensayos reformistas propuestos por algunos altos funcionarios en los años previos, junto a la movilización de las 
potencias del concierto europeo para poner freno a la extensión del constitucionalismo en el continente, llevó a muchos de los partidarios de una evolución tranquila de la monarquía piamontesa según el modelo franco-británico -que podía hacerse tomando como modelo la monarquía francesa o bien a través de la aplicación de la Constitución inglesa, que encontraba en la siciliana de 1812 una versión escrita adaptada a las condiciones italianas- a decantarse por la opción insurreccional. Así, la oposición, que incluía moderados y radicales, acudió a la conspiración a través de varias sociedades secretas. Todas las sensibilidades coincidían en la necesidad de dotar al reino de una constitución. El modelo francés fue perdiendo sus ventajas comparativas frente al español en el contexto de las revoluciones de 1820. Inicialmente, el modelo francés era el preferido por la mayor parte de las élites piamontesas, pero acabó imponiéndose la Constitución española. En este proceso fue fundamental la acción de las sociedades secretas, además de la evolución de la política internacional y en especial la intervención austriaca en Nápoles. Los "constitucionales a la española», como los llamaba un político local, fueron capaces de movilizar el patriotismo italiano en sus dos vertientes, nacional y liberal, insistiendo en la amenaza para la libertad y la unión italiana que representaban los austriacos. Los partidarios del modelo español llevaron a cabo una exitosa estrategia a favor de la Constitución gaditana en un contexto de cultura constitucional favorable y receptiva, y la opinión pública piamontesa se fue orientando hacia el modelo español. Finalmente, el código español acabó convenciendo a amplios sectores piamonteses de ser el más adecuado para ofrecer un encaje eficaz entre la monarquía y los derechos y libertades de una nación católica. Se siguió el modelo revolucionario español también en su faceta insurreccional, y las tropas estacionadas en Alejandría se sublevaron el 9 de marzo de 1821. Presionado, el regente Carlos Alberto optó por jurar la Constitución española: «La Constitución de España será promulgada y observada como ley del Estado, salvo aquellas modificaciones que la Representación Nacional, junto con su Majestad el rey, tenga a bien deliberar» (citado por Ferrando Badía, 1959: 139). Así, durante el breve periodo constitucional piamontés, pronto cercenado por la intervención austriaca, continuó la discusión acerca de la conveniencia o necesidad de reformar la Constitución española, que incluso algunos de los miembros del Gobierno consideraban extraña y en exceso revolucionaria. De nuevo, la incorporación de una segunda cámara fue una de las cuestiones principales. En Piamonte se hicieron pocos cambios al texto gaditano. Desde luego, los constitucionales piamonteses contaron con poco tiempo para desarrollar el sistema constitucional, y es probable que si la intervención austriaca no hubiera sido tan rápida, habrían dotado al reino de un texto adaptado a las circunstancias locales, tal y como habían hecho napolitanos y portugueses. 
El debate constitucional reanimado en el Mediterráneo en 1820-1821 se extendió inmediatamente al resto del continente. Tras la adopción de la Constitución de Cádiz en España, Portugal, Nápoles y Piamonte, sus méritos y deficiencias fueron objeto de vivas discusiones en Francia, Gran Bretaña, los Estados alemanes o Rusia. Este debate se desarrolló en torno a dos aspectos principales: la aplicabilidad de la Constitución española (o de cualquier constitución) a diferentes ambientes sociopolíticos y la conveniencia de realizar reformas a su texto original, tanto para adaptarlo a los contextos nacionales como para solucionar algunas de sus (supuestas) deficiencias. En este debate, la Constitución española fue regularmente comparada con la Carta francesa. Asimismo, en los países septentrionales se desarrolló un debate político en términos nacionales empleando como instrumentos de análisis los acontecimientos del sur del continente.

A partir de 1820 volvió a publicarse en toda Europa la Constitución española en viejas y nuevas traducciones, en ediciones en ocasiones aumentadas con documentos surgidos de la reciente revolución. Los debates fueron especialmente intensos en Francia, donde se pronunciaron los principales pensadores y políticos de todas las tendencias. Inmediatamente después del triunfo de la revolución española vieron la luz varias obras elogiosas con ella. En De la révolution actuelle en Espagne, De Pradt celebraba que los españoles -inesperadamente, por su supuesto retraso político- habían resuelto «un gran problema, el del establecimiento del gobierno representativo en Europa, y el del triunfo de la civilización moderna», y lo habían hecho de una manera ejemplar, a través de un «ejército ciudadano» (De Pradt, 1820: v-vii). En L'Europe et l'Amérique en 1821, De Pradt comparó la expansión internacional de la Constitución de Cádiz con las conquistas de Carlos V y Felipe II, aludiendo al retorno de España al ámbito internacional, ahora como potencia constitucional (De Pradt, 1822: 1). El interés por los asuntos españoles era compartido por conservadores y ultras, alarmados por la revolución al sur de sus fronteras, y por el asesinato del duque de Berry en febrero de 1820, que muchos creían directamente relacionado con los acontecimientos españoles. Numerosos autores dieron voz al pánico creado por la revolución de 1820 . Alphonse de Beauchamp calificó la Constitución española de «código de anarquía y despotismo", totalmente ilegítima por haber sido elaborada por unas Cortes que no habían seguido las prácticas tradicionales (De Beauchamp, 1822: 77). En alemán, pero rápidamente traducida a varias lenguas, apareció la que fue probablemente la obra más difundida de la condena reaccionaria, Análisis de la Constitución española, escrita por el suizo Karl-Ludwig von Haller. El libro condenaba la arrogancia de los filósofos y revolucionarios que creían que podían modificar las Leyes Fundamentales arrebatando al monarca la soberanía y alterando «la Constitución divina». El fruto de esos 
«fabricadores de constituciones», eran «leyes escritas sobre el papel, destinadas a ser el monopolio de algunos abogados» (citado por López Alós, 2009; véase también Escrig Rosa, 2016). Poco después de su publicación, varios autores cercanos al liberalismo, aunque críticos con la Constitución española, respondieron a Haller. François Guizot refutó sus acusaciones y defendió que en España había tenido lugar una revolución pacífica en la que se había tratado al rey con respeto (Guizot, 1820: 254-259). Jean-Denis Lanjuinais rechazó de plano los argumentos de un fanático como Haller, que escribía guiado por «la cólera", y que no "merece más que la compasión y el olvido" (citado por Basabe, 2012: 38).

En efecto, la condena de Haller era tan recalcitrante que al debate se unieron voces conservadoras de primera fila capaces de aportar argumentos juiciosos, como Chateaubriand o el futuro jefe del Gobierno, vizconde de Martignac. Ambos eran capaces de ofrecer argumentos de más vuelo a través de un análisis de la historia e instituciones españolas, para concluir que la Constitución de 1812 había sido fruto de unas Cortes ilegítimas que habían imitado a los revolucionarios franceses, y que la mayoría de la población española rechazaba la Constitución. Martignac, sin embargo, condenaba la deriva absolutista que estaba siguiendo la monarquía española, y abogaba por dotarla de un sistema basado en la antigua constitución (Basabe, 2012: 42-43).

El apoyo de los liberales franceses a los constitucionales españoles tenía más que ver con una lucha contra el avance en el interior de Francia de las posiciones ultras, que desde 1822 se confirmarían con el Gobierno de Villèle y, sobre todo, con el ascenso al trono del reaccionario Carlos X en 1823 (Skuy, 2003; Demier, 2012). Así, Guizot insistía en la calma con la que se había llevado a cabo la revolución española, que tanto la diferenciaba de la francesa, como prueba de que los sucesos al sur de los Pirineos no debían ser esgrimidos por los contrarrevolucionarios para justificar la necesidad de aprobar medidas reaccionarias. Pero a nivel teórico los doctrinarios franceses creían que la Constitución española era impracticable y que estaba condenada al fracaso. Pronosticaban que sus defectos, especialmente la problemática relación entre un vigoroso poder legislativo unicameral y un monarca débil, llevarían al país al conflicto permanente. De todas formas, al tiempo que los liberales moderados y doctrinarios criticaban el texto gaditano, se oponían a la intervención francesa en España, decidida en el Congreso de Verona en octubre de 1822. La oposición a la guerra de España movilizó a importantes segmentos de la sociedad francesa, como la prensa liberal, y llevó a episodios como la expulsión del diputado liberal Jacques-Antoine Manuel de la Cámara de los Diputados en febrero de 1823 (Caron, 2011). En este contexto polarizado, algunos sectores de la oposición parlamentaria —entre ellos el marqués de Lafayette y Benjamin Constant— abandonaron la vía política y apoyaron las 
iniciativas revolucionarias inspiradas en el modelo insurreccional meridional y que se plasmaron en varias conspiraciones fallidas (Spitzer, 1971; Neely, 1991; Simal, 2012: 138-142; Larroche, 2013).

En Gran Bretaña el constitucionalismo meridional se convirtió en un asunto de intensa confrontación política entre la oposición y el Gobierno, en especial cuando este decidió mantener una política de neutralidad ante las intervenciones de las potencias reaccionarias en los Estados constitucionales. La oposición británica impulsó en el Parlamento un debate sobre la no intervención, mientras surgían diversas iniciativas privadas de solidaridad con el constitucionalismo amenazado. En cualquier caso, la mayor parte de las élites políticas criticó los mismos aspectos de la Constitución española que habían sido objeto de reproche por parte de liberales y realistas franceses. La conservadora Quarterly Review reprochó la ausencia de una cámara alta y la debilidad del poder monárquico, y llegó a calificar de «democracia» el régimen político español. Por su parte, la publicación whig Edinburgh Review, que veía con simpatía la causa de los liberales españoles, no dejaba de reprobar todo aquello en lo que su constitución se alejaba del modelo británico y lo acercaba a los principios revolucionarios franceses, en especial el unicameralismo. Incluso los más fervientes partidarios de las revoluciones del sur de Europa criticaban algunos de sus aspectos, aunque con el propósito de contribuir a su éxito en unas circunstancias cambiantes. Jeremy Bentham valoró el texto gaditano desde el radicalismo, alejándose de la opinión dominante en su país. Bentham rechazaba la visión compartida por la mayoría de sus compatriotas de que el británico fuera un modelo constitucional ideal al que el resto de Europa debía tender. En este sentido, creía que la Constitución de Cádiz era un precedente más útil para otros países: «iPueblo de Europa! Si has dado gracias al Altísimo por haber puesto ante tus ojos el Código Constitucional español, da también gracias por no haber puesto ante ti la visión del código inglés», llegó a escribir. Bentham, muy crítico con el sistema de checks and balances de la Constitución británica, apoyaba el unicameralismo español. De todas formas, advertía algunos defectos en la Constitución de 1812 y aconsejó a portugueses y napolitanos que no adoptasen algunos de sus aspectos. En cualquier caso, algunas de las críticas de Bentham no fueron plenamente aceptadas por el conjunto del radicalismo británico (Fernández Sarasola, 2012; Alonso, 2014) ${ }^{6}$.

El debate constitucional impulsado por el constitucionalismo europeo meridional llegó a la India, contribuyendo a lo que C. A. Bayly ha denominado

6 Cita tomada de Rid yourselves of Ultramaria (1820), obra en la que Bentham criticaba duramente el tratamiento dado por los constitucionales españoles a los territorios de ultramar. 
«a global imagining of constitutional liberty». Miembros de la comunidad colonial portuguesa en Goa, radicales y «advanced Whigs» británicos (como los denominó el obispo Reginald Heber) residentes en Bengala, así como los precursores del liberalismo indio, entre los que destacaba Rammohan Roy, recibieron con entusiasmo la transformación constitucional de España y Portugal. La celebración del segundo aniversario de la proclamación del gobierno constitucional en Portugal que tuvo lugar en Calcuta en agosto de 1822 incluía rasgos propios de la cultural constitucional liberal que estaba surgiendo en Europa, como la realización de banquetes políticos. En esta ocasión, se ofrecieron brindis y se oyeron discursos a favor de «les libérales of France», Jeremy Bentham, los carbonarios y la reforma del Parlamento británico (Bayly, 2007: 28).

En los territorios europeos de habla alemana la Constitución española tuvo también un fuerte impacto. No faltaron apoyos a las revoluciones meridionales que destacaban la ausencia de violencia y la tranquilidad con que el cambio político había tenido lugar. August Heinrich Meisel aseguraba que la revolución española podía servir como un modelo para otros pueblos europeos en su camino hacia el constitucionalismo: «el conocimiento exacto de todos los elementos constitutivos de la revolución española es de extrema importancia, porque gracias a él los constitucionales pueden aprender lo que tiene que ocurrir y lo que tiene que haber para dar ese paso». Aparecieron significativas publicaciones elogiosas con el constitucionalismo mediterráneo, como el extenso artículo dedicado a España en el influyente diccionario político Conversations-Lexikon. La censura que el Conversations-Lexikon sufrió en Prusia y Austria desde 1822 vino motivada principalmente por este artículo (Ludwig, 2013; D’Aprile, 2014).

La revolución de 1820 apasionó a los futuros decembristas rusos, que, al igual que los europeos mediterráneos, sentían que pertenecían a un movimiento constitucional internacional. Según uno de los más destacados, Nikita Turgenev, «quizá España está demostrando la posibilidad de algo que hasta ahora creíamos imposible». El aristócrata Trubetskoi, que se colocaría en diciembre de 1825 al frente de las tropas sublevadas en la plaza del Senado de San Petersburgo, afirmó que se hizo constitucionalista por la adopción en Francia y otros países europeos de monarquías constitucionales con la aprobación de sus soberanos (citado por Stites, 2014: 12). Vladimir Shteingel afirmó que los «acontecimientos en España, Piamonte y Grecia inflamaron las mentes en Rusia acerca de la libertad», y el republicano Pavel Pestel concluyó que «todos estos acontecimientos familiarizaron las mentes de los hombres con la idea de revoluciones, y con sus posibilidades» (citado por Rabow, 2012: 154).

Además de participar en una discusión política abierta a la dimensión internacional, algunos pensadores extranjeros pretendieron intervenir en los 
procesos constituyentes de los países meridionales, en algunos casos con cierto impacto. El francés Lanjuinais escribió una obra haciendo recomendaciones para adaptar la Constitución española al Reino de las Dos Sicilias, que fue pronto traducida al italiano (Lanjuinais, 1820 y 1821). Especialmente activo fue Jeremy Bentham, que promovió la traducción de sus obras y mantuvo estrechos contactos con miembros de las Cortes y los Gobiernos portugueses y españoles, a los que realizó numerosas propuestas para mejorar, modificándolos, sus sistemas constitucionales (Fuller, 2000; Alonso, 2014).

\section{CONCLUSIÓN}

La Constitución española de 1812 y la Carta otorgada francesa de 1814 fueron adaptadas, en diferentes grados y circunstancias, por varios Estados europeos durante la Restauración. El texto español fue el preferido de aquellos que querían continuar la transformación política del continente tras la pausa impuesta en 1814-1815. La más moderada Carta francesa sirvió de modelo para aquellos que no renunciaban a hacer reformas, pero que creían necesario hacerlas de una manera sosegada, para de este modo evitar el estallido de una nueva revolución. Ambos paradigmas generaron intensos debates a lo largo de toda Europa —incluso más allá - y desafiaron con dispar suerte a las fuerzas reaccionarias que controlaban gran parte de los resortes de poder y de influencia social durante la Restauración.

La forma en la que se adoptó el código español a partir de 1820 en varios países muestra cómo, en el seno de una cultura constitucional transnacional, las constituciones podían ser concebidas como fetiches políticos. Los líderes de los pronunciamientos de Las Cabezas de San Juan, Nola, Oporto y Alejandría emplearon la Constitución redactada en Cádiz en 1812 principalmente como elemento de congregación política, como aglutinador de una oposición heterogénea a los regímenes restaurados. Para ellos, en un contexto en el que la Constitución se había convertido en la clave de la transformación política, era necesario disponer rápidamente de un código, incluso si este era foráneo. Así, la Constitución de Cádiz se convirtió en 1820 en un «tótem anti-absolutista» ${ }^{7}$ incluso para los iletrados o analfabetos, o, más bien, particularmente para ellos. Esta cultura constitucional aspiraba a llegar no solo a las élites, sino a capas de la población sin acceso reconocido a los resortes de la política institucional. El alcance de esta aspiración —y la respuesta del pueblo — presentó resultados variables, pero no conviene infravalorarla. La Constitución era, en

7 En expresión de Stites (2014: 139). 
primer lugar, un instrumento de movilización emocional. En España, según Dominique de Pradt: «[...] la adhesión [a la Constitución] ha precedido todo examen y toda reflexión. ¡La Constitución! ¡La Constitución! en la boca de los españoles quería decir solamente: Líbrennos de un gobierno insoportable y ya no querremos nada más» (1820: 175).

Los vintistas portugueses, los carbonarios napolitanos y los conspiradores piamonteses proclamaron la Constitución española para dar paso a otro tiempo político. Más adelante, un Parlamento constituyente se encargaría de elaborar un texto acomodado a las condiciones, usos y necesidades locales, adaptado incluso al carácter nacional. En este sentido, el articulado en sí no necesitaba ser conocido en detalle ni, por supuesto, su proclamación significaba que fuera a ser aplicado en su totalidad. Los liberales españoles no habían hecho otra cosa en enero de 1820.

A lo largo de este periodo es posible identificar un proceso por el cual diferentes culturas constitucionales locales convergieron progresivamente hacia una cultura constitucional transnacional, que no sustituyó a aquellas, sino que las complementó. De hecho, el debate constitucional transnacional fortaleció el desarrollo de las respectivas identidades nacionales, principalmente, pero no solo, en su vertiente cívica. Así, la existencia de una cultura constitucional, en gran medida compartida, facilitó la circulación y transmisión constitucional selectiva, en un proceso de emulación política. Era posible que un texto constitucional tuviera varias vidas, dependiendo del lugar donde fuera invocado. Las constituciones no significaban lo mismo en su país de origen que fuera de él. La Constitución española y la Carta francesa pudieron influir de la manera que lo hicieron en numerosos países europeos gracias a la manera en que fueron percibidas, más que a su contenido concreto. Al circular por Europa y ser adoptadas o empleadas en argumentaciones políticas de todo tipo por liberales y reaccionarios de otros orígenes, se resignificaron. El código constitucional en cuestión se convertía así en pieza de un debate más amplio, en el que era puesto al servicio de la ideología de aquel que lo invocaba para desarrollar argumentaciones relacionadas con la política interna y/o externa inmediata de su país - ya fuera pensador político, periodista, funcionario, militar, diplomático o un simple ciudadano-. Sin embargo, la existencia de transferencias que eran viables gracias a la existencia de una cultural constitucional de rasgos similares no significaba necesariamente un conocimiento profundo (o una lectura correcta o una interpretación acertada) del texto constitucional en cuestión. Las diversas constituciones del periodo pasaron a formar parte de un magma constitucional maleable, cambiante, adaptable, que servía intereses argumentativos diversos e incluso divergentes, en un mundo euroamericano crecientemente interconectado. 


\section{Bibliografía}

Aguilera, B. (2011). Influencia de la Constitución de Cádiz en Francia. En J. A. Escudero (dir.). Cortes y Constitución de Cádiz. 200 años (tomo III, pp. 499-514). Madrid: Espasa.

Alexander, R. (2003). Rewriting the French Revolutionary Tradition. Cambridge: Cambridge University Press. Disponible en: https://doi.org/10.1017/CBO9780511496653.

Alexeeva, T. (2011). La constitución española de 1812 y los decembristas rusos. En J. A. Escudero (dir.). Cortes y Constitución de Cádiz. 200 años (tomo III, pp. 524-542). Madrid: Espasa.

Alonso, G. (2014). "A Great People Struggling for Their Liberties»: Spain and the Mediterranean in the Eyes of the Benthamites. History of European Ideas, 41 (2), 194-204. Disponible en: https://doi.org/10.1080/01916599.2014.914308.

Basabe, N. (2012). Diez años de la Constitución de Cádiz en el debate político francés: 18141824. Historia Constitucional, 13, 23-72.

Bayly, C. A. (2007). Rammohan Roy and the advent of constitutional liberalism in India, 180030. Modern Intellectual History, 4 (1), 25-41. Disponible en: https://doi.org/10.1017/ S1479244306001028.

Berbel, M. R. (2008). A Constituiçao espanhola no mundo luso-americano (18201823). Revista de Indias, 68 (242), 225-254.

— (2012). Os sentidos de Cádis em Portugal e no Brasil de 1820 a 1823. En A. Annino y M. Ternavasio (coords.). El laberinto constitucional iberoamericano: 1807/1808-1830 (pp. 219-235). Madrid y Frankfurt am Main: AHILA/Iberoamericana/Vervuert.

Busaal, J. B. (2012). Le spectre du jacobinisme. L'expérience constitutionnelle de la Révolution française et le premier libéralisme espagnol (1808-1814). Madrid: Casa de Velázquez.

Butrón Prida, G. (2006). Nuestra Sagrada Causa. El modelo gaditano en la revolución piamontesa de 1821. Cádiz: Ayuntamiento de Cádiz.

Cabrera, M. Á. y Pro, J. (coords.) (2014). La creación de las culturas politicas modernas, 18081833. Madrid: Marcial Pons/Prensas Universitarias de Zaragoza.

Caron, J. C. (2011). Les mots qui tuent. Le meurtre parlementaire de Manuel (1823). Genèses, 83, 6-28. Disponible en: https://doi.org/10.3917/gen.083.0006.

Crăiutcu, A. (2003). Liberalism under Siege: The Political Thought of the French Doctrinaires. Lanham: Lexington Books.

Cruz Villalón, P. (2007). La Constitución de 1808 en perspectiva comparada. Cuadernos constitucionales de la Cátedra Fadrique Furió Ceriol, 58-59, 83-93.

D’Aprile, I. M. (2014). Historias interconectadas de los medios de comunicación y el desarrollo de un discurso constitucional europeo en los albores del siglo xIx. Ayer, 94, 49-69.

De Beauchamp, A. (1822). De la Révolution de l'Espagne et de sa crise actuelle. Paris: Ponthieu.

De Francesco, A. (1998). La Constitución de Cádiz en Nápoles. En J. M. Inurritegui y J. M. Portillo (eds.). Constitución en España: orígenes y destinos (pp. 273-286). Madrid: CEPC.

De Pradt, D. (1816). Mémoires historiques sur la révolution d'Espagne, par l'auteur du Congrès de Vienne, etc. París: Rosa-Perronneau.

- (1820). De la révolution actuelle en Espagne, et de ses suites. Paris: Béchet ainé-Rouen: Béchet fils. 
- (1822). L'Europe et L'Amérique en 1821, vol. II. Paris: Huzard-Coursier.

Delpu, P. M. (2014). Fraternités libérales et insurrections nationales: Naples et l'Espagne, 1820-1821. Revue d'histoire du XIXe siècle, 49, 195-213. Disponible en: https:// doi.org/10.4000/rh19.4762.

Demier, F. (2012). La France de la Restauration (1814-1830). L’impossible retour du passé. Paris: Folio-Histoire, Gallimard.

Dippel, H. (2009). Constitucionalismo moderno. Madrid: Marcial Pons.

Eastman, S. (2015). Introduction. The Sacred Mantle of the Constitution of 1812. En S. Eastman y N. Sobrevilla Perea (eds.). The Rise of Constitutional Government in the Iberian Atlantic World. The Impact of the Cádiz Constitution of 1812. Tuscaloosa: University of Alabama Press.

- (eds.) (2015). The Rise of Constitutional Government in the Iberian Atlantic World. The Impact of the Cádiz Constitution of 1812. Tuscaloosa: University of Alabama Press.

Escrig Rosa, J. (2016). Cadenas de papel. Un estudio del «Análisis de la Constitución Española» (1823) de Karl-Ludwig von Haller. Historia Constitucional, 17, 127-164.

Fernández Sarasola, I. (2004). Proyectos constitucionales en España (1786-1824). Madrid: CEPC.

- (ed.) (2007). Una Constitución para España: el Estatuto de Bayona. Madrid: Iustel.

- (2011). La Constitución de Cádiz. Origen, contenido y proyección internacional. Madrid: CEPC.

- (2012). La Constitución de Cádiz en Inglaterra. Historia Constitucional, 13, 1-21.

- (2015). Constitutional projects during the Spanish Enlightenment. En J. Astigarraga (ed.). The Spanish Enlightenment revisited (pp. 129-147). Oxford: Voltaire Foundation.

Fernández Sebastián, J. (2012). Entre el Espíritu Santo y el espíritu del siglo. Sobre la Constitución de las Cortes y el primer liberalismo hispano. Anthropos, 236, 55-75.

Ferrando Badía, J. (1959). La constitución española de 1812 en los comienzos del Risorgimento. Roma-Madrid: CSIC.

Fuller, C. (2000). «Primeiro e mais antigo Constitucional da Europa»: Bentham's contact with Portuguese liberals 1820-23. Journal of Bentham Studies, 3, 1-13. Disponible en: https:// doi.org/10.14324/111.2045-757X.012.

García Monerris, C. (2003). El debate 'preconstitucional': Historia y política en el primer liberalismo español (algunas consideraciones). En E. La Parra López y G. Ramírez Aledón (coords.). El primer liberalismo: España y Europa, una perspectiva comparada (pp. 39-77). Valencia: Biblioteca Valenciana.

- (2011). Notes à propos de la culture constitutionnelle en Espagne avant la Constitution de 1812. En J. P. Luis (coord.). La guerre d'Indépendance espagnole et le libéralisme au XIXe siècle (pp. 75-98). Madrid: Casa de Velázquez.

Ghervas, S. (2008). Réinventer la tradition: Alexandre Stourdza et l'Europe de la Sainte-Alliance. Paris: Honoré Champion.

Guizot, F. (1820). Du gouvernement de la France depuis la Restauration et du ministère actuel, 2a ed. Paris: Ladvocat.

Hill, H. B. (1936). The Constitutions of Continental Europe: 1789-1813. The Journal of Modern History, 8 (1), 82-94. Disponible en: https://doi.org/10.1086/468412.

Jarrett, M. (2013). The Congress of Vienna and Its Legacy: War and Great Power Diplomacy after Napoleon. London: I. B. Tauris. 
Jaume, L. (2003). Le libéralisme français après la Révolution, comparé au libéralisme anglais. Historia Constitucional, 4, 383-393.

Lanjuinais, J. D. (1820). Vues politiques sur les changements à faire à la Constitution de l'Espagne, afin de la consolider, spécialement dans le royaume de Deux-Siciles. Paris: Badouin Frères.

- (1821). Considerazioni politiche su cambiamenti da farsi alla Costituzione di Spagna per assodarla, specialemente nel regno delle Due-Sicilie. Nápoles: n.e.

Larroche, E. (2013). L'expédition d'Espagne. 1823: De la guerre selon la Charte. Rennes: Presses Universitaires de Rennes.

López Alós, J. (2009). «La constitución fabricada»: Haller, la restauración europea y España. Estudio introductorio a la edición de Análisis de la Constitución española en la Biblioteca Saavedra Fajardo. Disponible en: http://www.saavedrafajardo.org/Archivos/NOTAS/ RES0101.pdf.

Ludwig, J. (2013). Deutschland und die spanische Revolution, 1820-1823. Leipzig: Leipziger Universitätsverlag.

Mastroberti, F. (2014). Costituzioni e costituzionalismo tra Francia e Regno di Napoli (17961815). Bari: Cacucci.

Mendonça, M. (2011). Influência da Constituição espanhola de 1812 na portuguesa de 1822. En J. A. Escudero (dir.). Cortes y Constitución de Cádiz. 200 años (tomo III, pp. 481498). Madrid: Espasa.

Morange, C. (2006). Una conspiración falliday una constitución nonnata (1819). Madrid: CEPC.

Morelli, F. (2006). Tras las huellas perdidas de Filangieri: nuevas perspectivas sobre la cultura política constitucional en el Atlántico hispánico. Historia Contemporánea, 33, 431-461.

Moreno Alonso, M. (1997). La forja del liberalismo en España. Los amigos españoles de Lord Holland, 1793-1840. Madrid: Congreso de los Diputados.

Neely, S. (1991). Lafayette and the liberal ideal, 1814-1824. Politics and Conspiracy in an Age of Reaction. Carbondale y Edwardsville: Southern Illinois University Press.

Offord, D. (2012). The response of the Russian Decembrists to Spanish politics in the age of Ferdinand VII. Historia Constitucional, 13, 163-191.

Paquette, G. (2012). In the Shadow of Cádiz? Exogenous and Endogenous Factors in the Development of Portuguese Constitutionalism, c. 1780-1825. Bulletin for Spanish and Portuguese Historical Studies, 37 (2), artículo 6.

- (2013). Imperial Portugal in the Age of Atlantic Revolutions: The Luso-Brazilian World, c. 1770-1850. Cambridge: Cambridge University Press. Disponible en: https://doi. org/10.1017/CBO9781139237192.

Pérez Ledesma, M. y Sierra, M. (eds.) (2010). Culturas políticas. Teoría e historia. Zaragoza: Institución Fernando el Católico.

Portillo Valdés, J. M. (2000). Revolución de Nación. Orígenes de la cultura constitucional en España (1780-1812). Madrid: CEPC.

- (2006). Crisis atlántica. Autonomía e independencia en la crisis de la monarquía hispana. Madrid: Marcial Pons.

(2007). Constitucionalismo antes de la Constitución. La Economía Política y los orígenes del constitucionalismo en España. Nuevo Mundo Mundos Nuevos. Disponible en: doi: 10.4000/nuevomundo.4160. Disponible en: https://doi.org/10.4000/ nuevomundo.4160. 
Prutsch, M. J. (2013). Making Sense of Constitutional Monarchism in Post-Napoleonic France and Germany. Basingstoke: Palgrave Macmillan. Disponible en: https://doi. org/10.1057/9781137291653.

- (2014). Monarchical Constitutionalism in Post-Napoleonic Europe: Concept and Practice. En K. L. Grotke y M. J. Prutsch (eds.). Constitutionalism, Legitimacy, and Power. Nineteenth-Century Experiences (pp. 69-83). Oxford: Oxford University Press. Disponible en: https://doi.org/10.1093/acprof:oso/9780198723059.003.0004.

Rabow-Edling, S. (2012). The Decembrist Movement and the Spanish Constitution of 1812. Historia Constitucional, 13, 143-161.

Rausch, F. (2013). The impossible gouvernement représentatif: Constitutional Culture in Restoration France, 1814-1830. French History, 27 (2), 223-248. Disponible en: https:// doi.org/10.1093/fh/crt004.

Reyero, C. (2010). Alegoría, nación y libertad. El Olimpo constitucional de 1812. Madrid: Siglo XXI.

Rodríguez López-Brea, C. M. (2013a). La Constitución de Cádiz y el proceso revolucionario en las Dos Sicilias (1820-1821). Historia Contemporánea, 47, 561-594.

(2013b). El Viva la Pepa rebasa fronteras: los retoños de la Constitución de Cádiz. Revista de Historiografía, 20, 56-74.

Romano, A. (2011). Cádiz en Italia. La recepción de la constitución de Cádiz en Italia y la revolución piamontesa. En J. A. Escudero (dir.). Cortes y Constitución de Cádiz. 200 años (tomo III, pp. 459-472). Madrid: Espasa.

Rosanvallon, P. (1985). Le moment Guizot. París: Gallimard.

Schmidt-Nowara, C. (ed.) (2012). Global Horizons and Local Interests in the Era of the Constitution of Cadiz, número especial del Bulletin for Spanish and Portuguese Historical Studies, 37 (2).

Simal, J. L. (2012). Emigrados. España y el exilio internacional, 1814-1834. Madrid: Centro de Estudios Políticos y Constitucionales.

Skuy, D. (2003). Assassination, Politics, and Miracles: France and the Royalist Reaction of 1820. Montreal-Kingston-Ithaca-Nueva York: McGill-Queen's University Press.

Späth, J. (2012). Revolution in Europa 1820-1823. Verfassung und Verfassungskultur in den Königreichen Spanien, beider Sizilien und Sardinien-Piemont. Koln: SH Verlag.

Spini, G. (1950). Mito e realtà della Spagna nelle rivoluzione italiane del 1820-21. Roma: Perrella. Spitzer, A. B. (1971). Old Hatreds and Young Hopes. The French Carbonari against the Bourbon Restoration. Cambridge, Mass.: Harvard University Press.

Stites, R. (2014). The Four Horsemen. Riding to Liberty in Post-Napoleonic Europe. Oxford: Oxford University Press.

Varela Suanzes-Carpegna, J. (1992). El liberalismo francés después de Napoleón (de la anglofobia a la anglofilia). En Revista de Estudios Políticos, 76, 29-43.

- (2013). La monarquía doceañista (1810-1837). Avatares, encomios y denuestos de una extraña forma de gobierno. Madrid: Marcial Pons.

(2015). The image of the British system of government in Spain. En J. Astigarraga (ed.). The Spanish Enlightenment revisited (pp. 193-211). Oxford: Voltaire Foundation.

Vick, B. E. (2014). The Congress of Vienna. Power and Politics after Napoleon. Cambridge, Mass.: Harvard University Press. 
Vorländer, H. (2012). What is «Constitutional Culture»? En S. Hensel, U. Bock, K. Dircksen y H.-U. Thamer (eds.). Constitutional Cultures: On the Concept and Representation of Constitutions in the Atlantic World (pp. 21-41). Newcastle upon Tyne: Cambridge Scholars.

Wood, G. S. (1969). The Creation of the American Republic, 1777-1787. Chapel Hill: University of North Carolina Press. 